\title{
Psychometric properties of multicomponent tools designed to assess frailty in older adults: A systematic review
}

\author{
Jennifer L. Sutton ${ }^{1 *}$, Rebecca L. Gould', Stephanie Daley², Mark C. Coulson ${ }^{3}$, Emma V. Ward $^{3}$, Aine M. Butler ${ }^{1}$,
} Stephen P. Nunn ${ }^{3}$ and Robert J. Howard ${ }^{1,4}$

\begin{abstract}
Background: Frailty is widely recognised as a distinct multifactorial clinical syndrome that implies vulnerability. The links between frailty and adverse outcomes such as death and institutionalisation have been widely evidenced. There is currently no gold standard frailty assessment tool; optimizing the assessment of frailty in older people therefore remains a research priority. The objective of this systematic review is to identify existing multi-component frailty assessment tools that were specifically developed to assess frailty in adults aged $\geq 60$ years old and to systematically and critically evaluate the reliability and validity of these tools.

Methods: A systematic literature review was conducted using the standardised COnsensus-based Standards for the selection of health Measurement INstruments (COSMIN) checklist to assess the methodological quality of included studies.

Results: Five thousand sixty-three studies were identified in total: 73 of which were included for review. 38 multi-component frailty assessment tools were identified: Reliability and validity data were available for $21 \%$ (8/38) of tools. Only $5 \%(2 / 38)$ of the frailty assessment tools had evidence of reliability and validity that was within statistically significant parameters and of fair-excellent methodological quality (the Frailty Index-Comprehensive Geriatric Assessment [FI-CGA] and the Tilburg Frailty Indicator [TFI]).

Conclusions: The TFI has the most robust evidence of reliability and validity and has been the most extensively examined in terms of psychometric properties. However, there is insufficient evidence at present to determine the best tool for use in research and clinical practice. Further in-depth evaluation of the psychometric properties of these tools is required before they can fulfil the criteria for a gold standard assessment tool.
\end{abstract}

Keywords: Frailty, Assessment, Older adults

\section{Background}

It is estimated that between the years 2000 and 2050, the percentage of the world's population over 60 years old will double from 11 to $22 \%$ [1]. Frailty is considered one of the most complex and important issues associated with human ageing, with significant implications for both patient outcomes and healthcare service utilisation. The links between frailty and increased risk of

\footnotetext{
* Correspondence: jennifer.1.sutton@kcl.ac.uk

${ }^{1}$ Department of Old Age Psychiatry, Institute of Psychiatry, Psychology \& Neuroscience, King's College London, Box PO70, De Crespigny Park, London SE5 8AF, UK

Full list of author information is available at the end of the article
}

adverse outcomes such as falls, loss of functional independence, decreased quality of life, institutionalisation and mortality have been clearly evidenced [2-7].

A recent systematic review of frailty prevalence worldwide concluded that $10.7 \%$ of community dwelling adults aged $\geq 65$ years were frail and $41.6 \%$ pre-frail [8]. It was noted that prevalence figures varied substantially between studies (ranging from 4.0 to $59.1 \%$ ), with studies applying a physical phenotypical definition of frailty consistently reporting lower prevalence rates than those utilising a broader definition of frailty which included psychosocial domains [8]. This highlights the potential disparities in the 
identification of frailty depending on the definition of frailty applied.

The issue of identifying frailty is compounded by the fact that there is currently no universally accepted operational definition of frailty. A recent Delphi methods based consensus statement on frailty concluded that additional research into clinical and laboratory biomarkers of frailty is needed before an operational definition of frailty can be achieved [9]. However, expert agreement was reached on the basic theoretical underpinnings of frailty; the results of which were reflective of the defining characteristics of frailty for which there is a consensus in the literature. It is widely recognised that frailty is a distinct multifactorial clinical syndrome or state that is separate from, but often associated with, disease and disability [9-11]. Frailty is considered to be a dynamic, non-linear process characterised by decreased reserves and resistance resulting in poor maintenance of physiological homeostasis [10-12]. The dynamic nature of the frailty syndrome gives rise to the potential for preventative and restorative interventions.

Many models have been suggested to conceptualise frailty, however, at present there is no gold standard. The two models which have the largest evidence-base and are the most widely accepted are the Cardiovascular Health Study (CHS) Phenotype Model [13] and the Canadian Study of Health and Ageing (CSHA) Cumulative Deficit Model [14]. The CHS Phenotype Model [13] establishes a frailty phenotype with 5 variables (involuntary weight loss, self-reported exhaustion, slow gait speed, weak grip strength and self-reported sedentary behaviour), whereas the CSHA Cumulative Deficit Model [14] measures frailty via an index of age-related deficits including diseases and disabilities.

A wide variety of tools to screen for, diagnose and measure frailty have been developed based on models of frailty. However, at present no existing assessment tool is considered to be of a gold standard. In view of the predicted rise in the world's older adult population, the prevalence of frailty in this population, the evidenced links between frailty and adverse outcomes, and the potential for preventative and restorative interventions, the accurate assessment of frailty remains a significant clinical and research priority.

Six systematic reviews regarding the assessment of frailty have been published to date [15-20]. One review focused on the identification of frailty assessment tools [15]. Two reviews focused on the diagnostic test accuracy of frailty assessment tools; one reviewed the accuracy of simple measures to assess frailty [16] and one reviewed the sensitivity, specificity and predictive validity of instruments based on major theoretical views of frailty [17]. A further review examined the criterion validity, construct validity and responsiveness specifically of Frailty Indexes
[18]. These reviews focused on the appraisal of a specific subset of frailty assessment tools and did not examine all aspects of validity or explore the reliability of the tools identified. Only two reviews have reported an evaluation of both the reliability and validity of frailty assessment tools $[19,20]$; the literature searches for which were completed in February 2010 and May 2011, respectively. Given the current vast expansion of the frailty literature, an updated review in this area is justified. The evaluation of psychometric properties was not the sole focus in either review $[19,20]$. An in-depth evaluation of all available reliability and validity data for existing frailty assessment tools; including an assessment of both the methodological quality of the evidence presented and the statistical significance of the results has not been completed. Further, both of these earlier reviews included studies which reported the assessment of frailty via tools that were developed to assess alternative constructs such as disability rather than frailty per se. Tools that have been developed to assess alternate constructs will be based on alternative conceptual models and frameworks that do not represent all aspects of frailty; resulting in limited construct validity when applied to the measurement of frailty. Also, where a tool has been developed to measure a concept that is distinct from but linked to frailty, such as disability, there is a significant chance of confounding of the assessments results, leading to the inaccurate assessment and diagnosis of frailty based on disability factors alone. The inclusion of such tools in a review limits the conclusions that can be drawn in specific reference to the assessment of frailty. One review also included studies involving singlecomponent assessment tools such as grip strength as a single measure [19]. Given the multifactorial and complex nature of the frailty syndrome, a tool to assess frailty should be multicomponent to capture this multifactorial complexity and grounded within a robust evidence-based model of frailty. Tools originally created to assess an alternative concept but later applied to frailty assessment suggest a lack of theoretical robustness, as does the application of a single-component assessment tool to assess a multifactorial clinical syndrome. Consequently, the aims of this review were to: Systematically and critically evaluate the available evidence concerning the reliability and validity of multi-component frailty assessment tools that were specifically developed to assess frailty in older adult populations; establishing the tool with the best evidence to support its use in both research and clinical settings.

\section{Methods}

\section{Search strategy}

The following databases were searched on March 30 2015: Medline (1946-present), PsychINFO (1806-present), Embase (1947-present) and the Cochrane Central Register 
of Controlled Trials. The search strategy used was: frailty AND (older OR elder* OR geriatr*) AND (measure* OR assess"). The reference lists of previous reviews concerning the measurement of frailty were also searched manually [15-20].

\section{Selection criteria}

Studies were selected for inclusion for review if they met the following criteria:

- Study participants were aged $\geq 60$ years old.

- The study described a multi-component tool (defined as a tool that assesses $\geq 2$ indicators of frailty. Single-component tools were excluded due to the multifactorial and complex nature of the frailty syndrome).

- The study described a tool that was specifically developed to assess frailty (tools which were developed for alternative purposes and then applied to measure frailty were excluded as they do not exclusively assess frailty, but may assess related constructs such as disability resulting in a potentially invalid assessment of frailty and misdiagnosis).

- The main purpose of the study was the development and/or evaluation of the reliability and validity of a multi-component tool to assess frailty.

- The study applied the original version of a multi-component tool to assess frailty (studies citing modified versions were excluded as reliability and validity data relate to the modified tool only and reviewing all modified versions was beyond the scope of this review due to the large number of modified tools identified in the literature).

- The study reported quantitative data (the study must have reported inferential validation, studies reporting descriptive data alone were excluded).

- Studies were available in English or were translated wherever possible.

Studies were screened and selected for inclusion by JLS.

\section{Assessment of the methodological quality of studies and data extraction}

The COnsensus based Standards for the selection of health Measurement INstruments (COSMIN) checklist is a standardized tool for assessing the methodological quality of studies examining the measurement properties of health-related instruments [21-23]. It assesses measurement properties in a number of domains: Internal Consistency (the degree of the inter-relatedness among items), Reliability (the proportion of the total variance in measurements due to true differences among patients), Measurement Error (the systematic and random error of a patient's score that is not attributed to true changes in the construct to be measured), Content Validity (the degree to which the content of an instrument is an adequate reflection of the construct to be measured), Construct Validity (the degree to which the scores of an instrument are consistent with hypotheses based on the assumption that the instrument validly measures the construct to be measured), Criterion Validity (the degree to which the scores of an instrument are an adequate reflection of a gold standard ) and Responsiveness (the ability of an instrument to detect change over time in the construct to be measured) [22]. A 'gold standard measurement instrument is defined in the context of the COSMIN checklist as a valid and reliable instrument that has been widely accepted as a gold standard by experts in the field of its application [21-23].

Structural Validity (the degree to which the scores of an instrument are an adequate reflection of the performance of the dimensionality of the construct to be measured), Hypothesis Testing (item construct validity; the formulation of a hypothesis a priori with regard to correlations between the scores on the instrument and other variables e.g. with regard to internal relationships or relationships with scores on other instruments) and Cross Cultural Validity (the degree to which the performance of the items on a translated or culturally adapted instrument are an adequate reflection of the performance of the items of the original instrument) are assessed as part of Construct Validity [22].

With respect to scoring, each item in the COSMIN checklist is rated as excellent', good', fair', or poor' quality [21-23]. A rating of excellent' indicates that the evidence provided for that measurement property is adequate [21]. A rating of good' indicates that the evidence provided can be assumed to be adequate (although all relevant information may not be reported) [21]. Finally, ratings of fair' and poor' indicate that the evidence provided is questionable and inadequate, respectively [21].

The COSMIN checklist was applied to each study and data were extracted by two independent, blind raters (JLS, RLG, MCC, AMB, EVW, SD, SPN). Any disagreements were resolved through discussion. Data were then extracted regarding the methods and outcomes of the statistical analyses employed in each study to assess the identified measurement properties of each assessment tool. The outcomes of the statistical analyses employed by each study were compared to the accepted statistical parameters of significance for said test as identified in medical statistics literature (see Additional file 1 footnote). This allowed for the identification of statistically significant evidence of measurement properties testing. 


\section{Reporting}

This review followed the PRISMA standards [24] for reporting of systematic reviews (see Additional file 2).

\section{Results}

Literature search and inclusion for review

Five thousand sixty-three studies were identified in total, 73 of which were included for review following assessment against inclusion criteria (see Fig. 1) [2, 13, 25-95].

\section{Study characteristics}

Thirty-eight multi-component frailty assessment tools were examined in 73 studies. The most frequently examined tool with respect to psychometric properties was the Groningen Frailty Indicator (GFI), which was assessed in 11 studies [27, 49, 54-62]. The Tilburg Frailty Indicator (TFI) was also frequently examined, with 9 studies included for review [55, 57, 88-94]. Psychometric properties were assessed in 1 study only for $22 / 38$ tools [25, 28-30, 34, 38, 44, 48, 51-53, 63, 66-68, 71-73, 79, 86, 87, 95]. Prospective Cohort was the most frequently observed study design (22/73 studies) [2, 13, 25-29, 31-33, 47, 48, $53,55,60,66,67,72,80,81,86,95]$. In $54 / 73$ studies the cohort was exclusively community-based $[2,13,25,26,29$, $31,33,34,38-40,45,46,48-50,52-56,59,63-67,70,71$, 73-95]. The country from which participants were most commonly sampled was The Netherlands (26/73 studies) $[39,40,44,49,50,54-63,65,72,74-81,89-93]$. Followup data were available for $51 / 73$ studies; follow-up periods varied significantly with the shortest being 1 month [35] and the longest 348 months [33]. Data regarding the mean age of participants were available in 55/73 studies; the overall mean age of the participants as calculated by pooling the mean ages from these 55 studies was 77.0 years $[2,25,27,28,30,32,33,35-42,44,47-50,52-59,61-$ $65,67-69,72,74-76,79-84,86-94]$. A full outline of study characteristics is provided in Additional file 3.

\section{Methodological quality of studies}

The results of the COSMIN checklist are summarised in Table 1. 38/73 studies included for review had at least one area of methodological quality rated as poor', indicating inadequate quality $[27,29-35,38-41,43,44,46$, 49, 51-57, 60, 61, 67-70, 74, 75, 78, 81, 82, 85, 86, 90, 94]. The measurement property that received the highest number of poor ratings across all studies was Criterion Validity (23/44 total poor' ratings). 52/73 studies had at least one area of methodological quality rated as fair', indicating questionable methodological quality $[2,13,25$, $26,28,30,31,34-39,42,44-50,54-56,60-67,71-81,83$, 85-87, 91-93, 95]. The measurement property that received the highest number of fair' ratings was Hypothesis Testing (50/64 total fair' ratings). 2/73 studies had one area of methodological quality scored as good', indicating presumably adequate methodological quality $[57,58]$. All ratings of good' quality were awarded for Hypothesis Testing. 6/73 studies had one area of methodological quality scored as excellent', indicating adequate methodological quality $[25,31,54,67,74,79,84]$. All ratings of excellent' were awarded for Content Validity.

\section{Psychometric properties of the multi-component frailty assessment tools}

Table 1 provides an overview of the measurement properties of each multi-component frailty assessment tool. The tools that have been examined the most with respect to psychometric domains were the TFI and GFI. The TFI had 8 of the possible 9 domains explored (the exception being Measurement Error) [55, 57, 88-94]. The GFI had $7 / 9$ domains examined (the exceptions being Measurement Error and Cross Cultural Validity) [27, 49, 54-62]. The tools that were examined the least with respect to psychometric domains were Frailty predicts death One yeaR after Elective Cardiac Surgery Test (FORECAST) [36, 37], Guilley Frailty Instrument [63], Self-Report

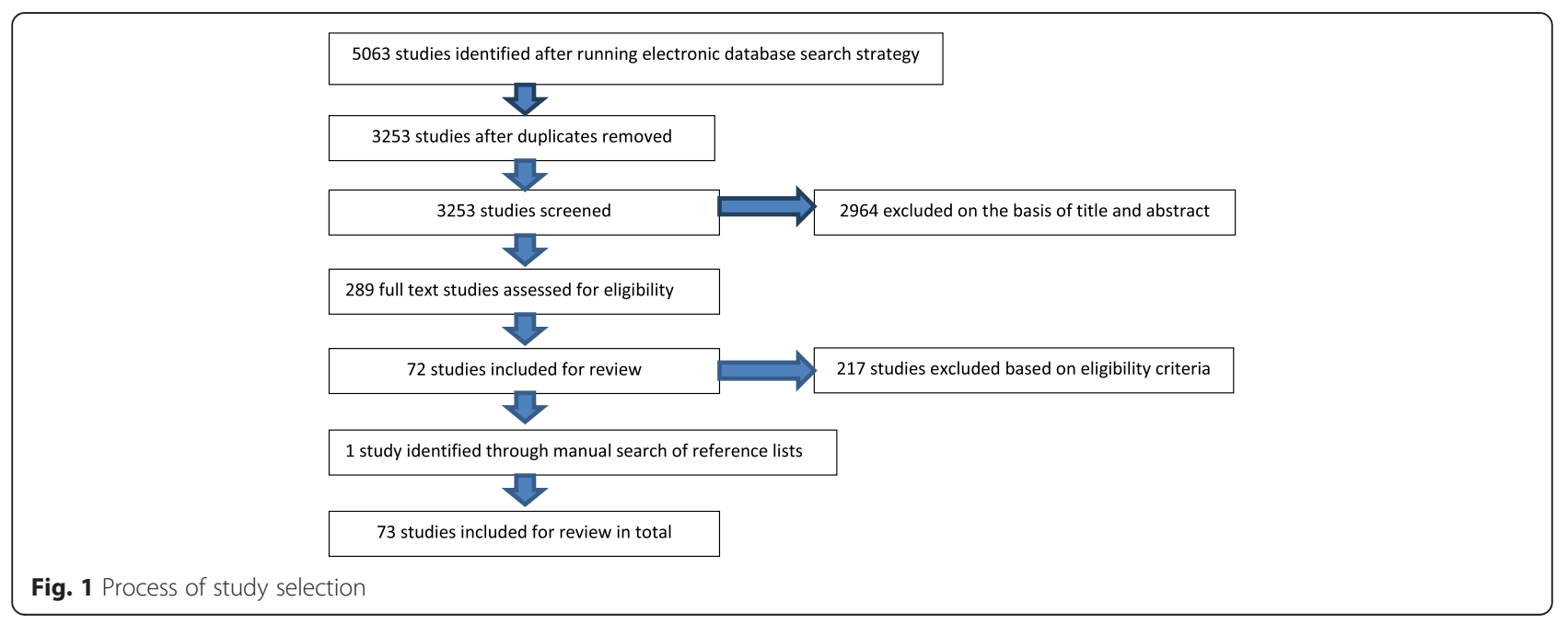


Table 1 Results of COnsensus-based Standards for the selection of health Measurement Instruments (COSMIN) Checklist

\begin{tabular}{|c|c|c|c|c|c|c|c|c|c|c|c|}
\hline Frailty assessment tool & Study reference & $\begin{array}{l}\text { Internal } \\
\text { consistency }\end{array}$ & Reliability & $\begin{array}{l}\text { Measurement } \\
\text { error }\end{array}$ & $\begin{array}{l}\text { Content } \\
\text { validity }\end{array}$ & $\begin{array}{l}\text { Structural } \\
\text { validity }\end{array}$ & $\begin{array}{l}\text { Hypotheses } \\
\text { testing }\end{array}$ & $\begin{array}{l}\text { Cross-cultural } \\
\text { validity }\end{array}$ & $\begin{array}{l}\text { Criterion } \\
\text { validity }\end{array}$ & Responsiveness & Comments \\
\hline 9-Item Frailty Measure & $\begin{array}{l}\text { Ravaglia et al. } \\
\text { [25] }\end{array}$ & 0 & 0 & 0 & 4 & - & 2 & 0 & 0 & 0 & $\begin{array}{l}\text { Structural Validity: Not rated according } \\
\text { to COSMIN guidance as the tool is } \\
\text { based on a formative model. }\end{array}$ \\
\hline
\end{tabular}

Brief Clinical Instrument Rockwood et al. 0 to Classify Frailty [26]

Kenig et al. [27]

Brief Frailty Index

British Frailty Index [28]

Kamaruzzaman -

et al. [29]

Goldstein et al.

[30]

Index-Comprehensive

Geriatric Assessment

(CP-FI-CGA)

Clinical Frailty Scale

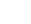

Rockwood et al. 0
[31]

0

0

1

0

0 based on a formative model.

Criterion Validity: Study reports

assessment of criterion validity however this is rated as part of construct validity (hypothesis testing) according to

COSMIN guidance.

Hypothesis Testing: Important

methodological flaws in the design of the study noted; diagnosis of frailty via the detection of deficits in two or more domains of the Geriatric Assessment

(GA) has limited theoretical grounding. No reliability or validity data for GA in this context.

Internal Consistency: Not rated according to COSMIN guidance as the tool is based on a formative model. Criterion Validity: The criterion

Criterion Validity: The criterion
employed cannot be considered a reasonable gold standard. Correlations or AUC of ROC not calculated.

Criterion Validity: The criterion employed cannot be considered as a reasonable gold standard.

Reliability: Tool not administered by independent raters when assessing inter-rater reliability.

Criterion Validity: The criterion

employed cannot be considered as a

reasonable gold standard. 
Table 1 Results of COnsensus-based Standards for the selection of health Measurement Instruments (COSMIN) Checklist (Continued)

Rockwood et al. 0 [32]

Mitiniski et al. $\quad 0$

Studenski et al.

Clinical Global

Impression of Chang

in Physical Frailty

Comprehensive

Assessment of Frailty

Sundermann

et al. [35]

(CA
(1)

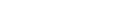

1

$\begin{array}{ll}\begin{array}{l}\text { Sundermann } \\ \text { et al. [36] }\end{array} & 0 \\ \text { Sundermann } & 0 \\ \text { et al. [37] } & \end{array}$

et al. [37]

(1)

(1)

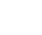

2

0

0

0

0

0

.
0

0
Criterion Validity: The criterion

employed cannot be considered as a reasonable gold standard.

Criterion Validity and Hypothesis

Testing: Important methodological
flaws in the design of the study noted

measurement properties of comparator

instrument (Phenotype of frailty-

Referred to as Frail-CHS) significantly

altered from original. No reliability or

validity data for amended version.

Construct Validity: Important

methodological flaws in the design of

the study noted; measurement

properties of comparator instrument

(Phenotype of Frailty) significantly

altered from original. No reliability or

validity data for amended version.

Reliability: Inter-rater reliability assessed using case scenarios. Small sample size $(n=24)$ for pilot testing. Likely

selection bias in the focus group; all

patients and carers selected by first

author (all carers were female). Likely

selection bias for participants of pilot

test as the testing physicians chose two

patients who they deemed to be

frail to be tested.

Content validity: Some aspects of content validity explored however there was limited assessment of whether all items are relevant for the study population and limited

information regarding the theoretical foundation of the tool.

Structural validity: Not rated according

to COSMIN guidance as the tool is

based on a formative model. 
Table 1 Results of COnsensus-based Standards for the selection of health Measurement Instruments (COSMIN) Checklist (Continued)

\begin{tabular}{llllllllll}
\hline Continuous Composite & Buchman et al. & 0 & 0 & 0 & 2 & 0 & 2 & 0 & 1
\end{tabular}

Measure of Frailty

$\begin{array}{ll}1 & 1\end{array}$

Van Kempen $\quad 0$

EASY-Care Two-step

Older persons

et al. [39]

(Easycare TOS)

Van Kempen

et al. [40]

Edmonton Frail Scale

Haley et al. [42] 0

Graham et al. 0

[43]

Evaluative Index for

Physical Frailty

Frailty Index-

Comprehensive

Geriatric Assessment

(FI-CGA)

\begin{abstract}
De Vries et al.
\end{abstract}
[44]

Jones et al. [45]

Jones et al. [46] 0

Pilotto et al.

[47]

(a)

Criterion Validity: The criterion

employed cannot be considered as a reasonable gold standard.

Measurement properties of comparator instrument (Phenotype of Frailty) significantly altered from original. No reliability or validity data for amended version.

Responsiveness: The time interval

between measurements was not adequately described.

Reliability: Small sample size $(n=19)$ for reliability calculations.Criterion Validity:

The criterion employed cannot be considered as a reasonable gold standard.

Content Validity: An assessment of whether all items are relevant for the purpose of the measurement

instrument was competed however limited information available regarding other aspects of content validity.

Internal Consistency: Not rated according to COSMIN guidance as the tool is based on a formative model. Reliability: Small sub sample size $(n=18)$ for reliability calculations.

Hypothesis Testing: Important

methodological flaws in the design of the study noted; tertile split was performed for reasons of sample size equality and not theoretically or

empirically justified.

Reliability and Hypothesis testing: Small sample $(n=24)$

Criterion Validity: The criterion

employed cannot be considered as a reasonable gold standard. 
Table 1 Results of COnsensus-based Standards for the selection of health Measurement Instruments (COSMIN) Checklist (Continued)

\begin{tabular}{|c|c|c|c|c|c|c|c|c|c|c|c|}
\hline \multirow[t]{2}{*}{ FORECAST } & $\begin{array}{l}\text { Sundermann } \\
\text { et al. [35] }\end{array}$ & 0 & 0 & 0 & 0 & 0 & 2 & 0 & 0 & 0 & \\
\hline & $\begin{array}{l}\text { Sundermann } \\
\text { et al. [36] }\end{array}$ & 0 & 0 & 0 & 0 & 0 & 2 & 0 & 0 & 0 & \\
\hline Frailty Index & $\begin{array}{l}\text { Mitnitski et al. } \\
{[48]}\end{array}$ & 0 & 0 & 0 & 0 & 0 & 2 & 0 & 0 & 0 & \\
\hline \multirow[t]{2}{*}{$\begin{array}{l}\text { Frailty Index based on } \\
\text { Primary Care Data. }\end{array}$} & $\begin{array}{l}\text { Drubbel et al. } \\
\text { [49] }\end{array}$ & 0 & 0 & 0 & 2 & 0 & 2 & 0 & 1 & 0 & $\begin{array}{l}\text { Criterion Validity: The criterion } \\
\text { employed cannot be considered as a } \\
\text { reasonable gold standard. }\end{array}$ \\
\hline & $\begin{array}{l}\text { Drubbel et al. } \\
\text { [50] }\end{array}$ & 0 & 0 & 0 & 2 & 0 & 2 & 0 & 0 & 0 & \\
\hline $\begin{array}{l}\text { Frailty Index for Elders } \\
\text { (FIFE) }\end{array}$ & $\begin{array}{l}\text { Tocchi et al. } \\
\text { [51] }\end{array}$ & - & 0 & 0 & 1 & - & 0 & 0 & 0 & 0 & $\begin{array}{l}\text { Internal Consistency \& Structural } \\
\text { Validity: Not rated according to } \\
\text { COSMIN guidance as the tool is based } \\
\text { on a formative model. } \\
\text { Content Validity: Important } \\
\text { methodological flaws in the design of } \\
\text { the study noted; during item } \\
\text { generation process potential variables } \\
\text { excluded solely on the basis of } \\
\text { information available in the parent } \\
\text { data set. }\end{array}$ \\
\hline $\begin{array}{l}\text { Frail Non-Disabled } \\
\text { Instrument (FiND) }\end{array}$ & Cesari et al. [52] & 0 & 0 & 0 & 1 & 0 & 1 & 0 & 1 & 0 & $\begin{array}{l}\text { Content Validity, Hypothesis Testing } \\
\text { and Criterion Validity: Important } \\
\text { methodological flaws in the design of } \\
\text { the study noted; Analysis of agreement } \\
\text { between FiND and Phenotype of } \\
\text { Frailty is flawed as FiND includes } 2 / 5 \text { of } \\
\text { the Phenotype of Frailty items. This } \\
\text { significantly affects the interpretation } \\
\text { of the data. }\end{array}$ \\
\hline Frailty Screening Tool & Doba et al. [53] & 0 & 0 & 0 & 1 & - & 1 & 0 & 0 & 0 & $\begin{array}{l}\text { Structural Validity: Not rated according } \\
\text { to COSMIN guidance as the tool is } \\
\text { based on a formative model. } \\
\text { Content validity \& Hypothesis Testing: } \\
\text { Important methodological flaws in the } \\
\text { design of the study noted; potential } \\
\text { selection bias due to the exclusion of } \\
\text { those older adults who had chronic } \\
\text { comorbid illness. Potential } \\
\text { underrepresentation of frailest adults } \\
\text { due to the exclusion of participants } \\
\text { from analysis whom were unable to } \\
\text { engage in a final assessment. No clarity } \\
\text { regarding the definition of 'cognitive } \\
\text { change' item. }\end{array}$ \\
\hline
\end{tabular}

ncy \& Structura

Validity: Not rated according to

on a formative model.

methodological flaws in the design of

the study noted; during item

eneration process potential variables

ded solely on the basis of

data set.

Content Validity, Hypothesis Testing

and Criterion Validity: Important

Frailty is flawed as FiND includes 2/5 of

Structural Validity: Not rated according

esign of the study noted; potentia

change' item. 
Table 1 Results of COnsensus-based Standards for the selection of health Measurement Instruments (COSMIN) Checklist (Continued)

\begin{tabular}{llllllllll}
\hline Groningen Frailty & Bielderman & - & 0 & 0 & 4 & - & 2 & 0 & 1
\end{tabular}

\section{Daniels et al. $\quad 0$}

[55]

Drubbel et al. $\quad 0$

[49]

Hoogendijk

et al. [56]

Kenig et al. [27] 0

[57]

Peters et al. [58]

Schuurmans

et al. [59]

Smets et al. [60] 0

0

0

0

0

0

0

0

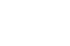

$-$

3

0

0

(1)

0

0

0

$\begin{array}{llllll}0 & - & 3 & 0 & 0 & 0 \\ 0 & 0 & 2 & 0 & 0 & 0 \\ 0 & 0 & 2 & 0 & 1 & 0\end{array}$

Internal Consistency and Structural
Validity: Not rated according to

COSMIN guidance as the tool is based

on a formative model.

Criterion Validity: The criterion

employed cannot be considered as a

reasonable gold standard.

Criterion Validity: The criterion

employed cannot be considered as a

reasonable gold standard.

Criterion Validity: The criterion

employed cannot be considered as a

reasonable gold standard.

Criterion Validity: The criterion

employed cannot be considered as a reasonable gold standard.

Hypothesis Testing: Important

methodological flaws in the design of the study noted; diagnosis of frailty via the detection of deficits in two or more domains of the Geriatric

Assessment has limited theoretical grounding. No reliability or validity data for GA in this context.

Internal Consistency and Structural Validity: Not rated according to

COSMIN guidance as the tool is based on a formative model.

Criterion Validity: The criterion

employed cannot be considered as a reasonable gold standard.

Internal Consistency and Structura

COSMIN guidance as the tool is based on a formative model.

Criterion Validity: The criterion

employed cannot be considered as a reasonable gold standard. 
Table 1 Results of COnsensus-based Standards for the selection of health Measurement Instruments (COSMIN) Checklist (Continued)

\section{Guilley Frailty}

Instrument

Inactivity and Weight

Loss

INTER-FRAIL Study

Questionnaire

KLoSHA Frailty Index

Chin et al. [64] 0

Chin et al. [65] 0

De Bari et al. 0

[66]

Jung et al. [67]

0

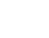

$0 \quad 0$

Marigliano-Cacciafesta Polypathological Scale
Amici et al. [68] 0

0

0

0
0
2
0
2
4

0
0
0
0

2
2
2
2
2
2

0
0
0
0
0
0

0

Internal Consistency: Not rated

according to COSMIN guidance as the

tool is based on a formative model.

Reliability: Limited information

regarding basic inter-rater reliability

calculations given. No further reliability calculations completed.

Content Validity: Limited assessment of whether all items are relevant for the

study population. Limited information

due to source being a poster

presentation abstract.

Structural Validity: Not rated according to COSMIN guidance as the tool is based on a formative model.

Criterion Validity: The criterion

employed cannot be considered as a reasonable gold standard.

Hypothesis testing and Criterion

Validity: Important methodological

flaws in the design of the study noted; analysis consists purely of correlations with limited theoretical justification.

Criterion Validity: The criterion

employed cannot be considered as a

reasonable gold standard.

$\begin{array}{lllllllllll}\text { Phenotype of Frailty } & \text { Esrund et al. [2] } & 0 & 0 & 0 & 0 & 0 & 2 & 0 & 0 \\ & \text { Fried et al. [13] } & 0 & 0 & 0 & 0 & 0 & 2 & 0 & 0 \\ & \text { Kenig et al. [27] } & 0 & 0 & 0 & 0 & 0 & 1 & 0 & 0 \\ \end{array}$

\section{Hypothesis Testing: Important}

methodological flaws in the design of the study noted; diagnosis of frailty via the detection of deficits in two or more domains of the Geriatric

Assessment has limited theoretical grounding. No reliability or validity data for GA in this context. 
Table 1 Results of COnsensus-based Standards for the selection of health Measurement Instruments (COSMIN) Checklist (Continued)

\begin{tabular}{|c|c|c|c|c|c|c|c|c|c|c|}
\hline & Kim et al. [69] & 0 & 0 & 0 & 0 & 0 & 0 & 0 & 1 & 0 \\
\hline & $\begin{array}{l}\text { Kulminski et al. } \\
{[70]}\end{array}$ & 0 & 0 & 0 & 0 & 0 & 0 & 0 & 1 & 0 \\
\hline $\begin{array}{l}\text { Predictive Physical } \\
\text { Frailty Score }\end{array}$ & $\begin{array}{l}\text { Carriere et al. } \\
\text { [71] }\end{array}$ & 0 & 0 & 0 & 0 & - & 2 & 0 & 0 & 0 \\
\hline Prognostic Risk Score & $\begin{array}{l}\text { Pijpers et al. } \\
\text { [72] }\end{array}$ & 0 & 0 & 0 & 0 & - & 2 & 0 & 0 & 0 \\
\hline $\begin{array}{l}\text { Self-Report Screening } \\
\text { Tool for Frailty }\end{array}$ & $\begin{array}{l}\text { De Souto } \\
\text { Barreto et al. } \\
\text { [73] }\end{array}$ & 0 & 0 & 0 & 0 & 0 & 2 & 0 & 0 & 0 \\
\hline \multirow[t]{5}{*}{$\begin{array}{l}\text { SHARE Frailty } \\
\text { Instrument }\end{array}$} & $\begin{array}{l}\text { Romero-Ortuno } \\
\text { et al. [74] }\end{array}$ & 0 & 0 & 0 & 4 & - & 2 & 0 & 1 & 0 \\
\hline & $\begin{array}{l}\text { Romero-Ortuno } \\
\text { et al. [75] }\end{array}$ & 0 & 0 & 0 & 0 & 0 & 2 & 0 & 1 & 0 \\
\hline & $\begin{array}{l}\text { Romero-Ortuno } \\
\text { et al. [76] }\end{array}$ & 0 & 0 & 0 & 0 & 0 & 2 & 0 & 0 & 0 \\
\hline & $\begin{array}{l}\text { Romero-Ortuno } \\
\text { et al. [77] }\end{array}$ & 0 & 0 & 0 & 0 & 0 & 2 & 0 & 0 & 0 \\
\hline & $\begin{array}{l}\text { Romero-Ortuno } \\
\text { et al. [78] }\end{array}$ & 0 & 0 & 0 & 0 & 0 & 2 & 0 & 1 & 0 \\
\hline $\begin{array}{l}\text { SHARE Frailty } \\
\text { Instrument } 75+ \\
\text { (SHARE-FI75+) }\end{array}$ & $\begin{array}{l}\text { Romero-Ortuno } \\
\text { et al. [79] }\end{array}$ & - & 0 & 0 & 4 & - & 2 & 0 & 0 & 0 \\
\hline SOF Frailty Criteria & $\begin{array}{l}\text { Bilotta et al. } \\
\text { [80] }\end{array}$ & 0 & 0 & 0 & 0 & 0 & 2 & 0 & 0 & 0 \\
\hline
\end{tabular}

Criterion Validity: The criterion employed cannot be considered as a reasonable gold standard. No calculations of sensitivity and specificity.

Criterion Validity: The criterion

employed cannot be considered as a reasonable gold standard. Scoring changed from ordinal to continuous however only relative risk ratios were compared. No correlations or AUC of ROC calculated.

Structural Validity: Not rated according to COSMIN guidance as the tool is based on a formative model.

Structural Validity: Not rated according to COSMIN guidance as the tool is based on a formative model.

Structural Validity: Not rated according to COSMIN guidance as the tool is based on a formative model. Criterion Validity: The criterion

employed cannot be considered as a reasonable gold standard.

Criterion Validity: The criterion

employed cannot be considered as a reasonable gold standard.

Criterion Validity: The criterion employed cannot be considered as a reasonable gold standard.

Internal Consistency \& Structura Validity: Not rated according to COSMIN guidance as the tool is based on a formative model. 
Table 1 Results of COnsensus-based Standards for the selection of health Measurement Instruments (COSMIN) Checklist (Continued)

\begin{tabular}{|c|c|c|c|c|c|c|c|c|c|c|c|}
\hline & $\begin{array}{l}\text { Ensrud et al. } \\
\text { [81] }\end{array}$ & 0 & 0 & 0 & 0 & 0 & 2 & 0 & 1 & 0 & $\begin{array}{l}\text { Criterion Validity: The criterion } \\
\text { employed cannot be considered as a } \\
\text { reasonable gold standard. }\end{array}$ \\
\hline \multirow[t]{2}{*}{$\begin{array}{l}\text { Strawbridge Frailty } \\
\text { Measure }\end{array}$} & $\begin{array}{l}\text { Strawbridge } \\
\text { et al. [82] }\end{array}$ & 0 & 0 & 0 & 1 & 0 & 0 & 0 & 0 & 0 & $\begin{array}{l}\text { Content validity: No assessment of } \\
\text { whether all items are relevant for the } \\
\text { target population and no assessment } \\
\text { of whether all items together } \\
\text { comprehensively reflect the } \\
\text { measurement of frailty. }\end{array}$ \\
\hline & $\begin{array}{l}\text { Matthews et al. } \\
\text { [83] }\end{array}$ & 0 & 0 & 0 & 0 & 0 & 2 & 0 & 0 & 0 & \\
\hline \multirow[t]{2}{*}{$\begin{array}{l}\text { The Comprehensive } \\
\text { Frailty Assessment } \\
\text { Instrument }\end{array}$} & $\begin{array}{l}\text { De Witte et al. } \\
\text { [84] }\end{array}$ & - & 0 & 0 & 4 & - & 0 & 0 & 0 & 0 & $\begin{array}{l}\text { Internal Consistency \& Structural } \\
\text { Validity: Not rated according to } \\
\text { COSMIN guidance as the tool is based } \\
\text { on a formative model. }\end{array}$ \\
\hline & $\begin{array}{l}\text { De Witte et al. } \\
\text { [85] }\end{array}$ & - & 0 & 0 & 0 & 0 & 2 & 0 & 1 & 0 & $\begin{array}{l}\text { Internal consistency: Not rated } \\
\text { according to COSMIN guidance as the } \\
\text { tool is based on a formative model. } \\
\text { Criterion Validity: The criterion } \\
\text { employed cannot be considered as a } \\
\text { reasonable gold standard. }\end{array}$ \\
\hline The Frailty Trait Scale & $\begin{array}{l}\text { Garcia-Garcia } \\
\text { et al. [86] }\end{array}$ & 0 & 0 & 0 & 2 & 0 & 2 & 0 & 1 & 0 & $\begin{array}{l}\text { Criterion Validity: The criterion } \\
\text { employed cannot be considered as a } \\
\text { reasonable gold standard. }\end{array}$ \\
\hline The FRAIL Scale & Lopez et al. [87] & 0 & 0 & 0 & 0 & 0 & 2 & 0 & 0 & 0 & \\
\hline \multirow[t]{5}{*}{$\begin{array}{l}\text { Tilburg Frailty Indicator } \\
\text { (TFI) }\end{array}$} & $\begin{array}{l}\text { Andreasen } \\
\text { et al. [88] }\end{array}$ & 0 & 0 & 0 & 0 & 0 & 0 & 1 & 0 & 0 & $\begin{array}{l}\text { Cross-Cultural Validity: Sample size less } \\
\text { than } 5 \text { times the number of items } \\
\text { included on the scale }\left(5^{*} 15=75 \text {, }\right. \\
\text { actual sample size included; } 34)\end{array}$ \\
\hline & $\begin{array}{l}\text { Daniels et al. } \\
\text { [55] }\end{array}$ & 0 & 0 & 0 & 0 & 0 & 2 & 0 & 1 & 2 & $\begin{array}{l}\text { Criterion Validity: The criterion } \\
\text { employed cannot be considered as a } \\
\text { reasonable gold standard. }\end{array}$ \\
\hline & $\begin{array}{l}\text { Gobbens \& van } \\
\text { Assen [89] }\end{array}$ & 0 & 0 & 0 & 0 & 0 & 2 & 0 & 0 & 0 & \\
\hline & $\begin{array}{l}\text { Gobbens et al. } \\
\text { [90] }\end{array}$ & 0 & 0 & 0 & 1 & 0 & 0 & 0 & 0 & 0 & $\begin{array}{l}\text { Content Validity: An assessment of } \\
\text { whether all items are relevant for the } \\
\text { purpose of the measurement } \\
\text { instrument was competed however } \\
\text { there was limited information } \\
\text { regarding other aspects of content } \\
\text { validity. }\end{array}$ \\
\hline & $\begin{array}{l}\text { Gobbens et al. } \\
\text { [91] }\end{array}$ & 0 & 2 & 0 & 2 & 0 & 2 & 0 & 0 & 0 & \\
\hline
\end{tabular}


Table 1 Results of COnsensus-based Standards for the selection of health Measurement Instruments (COSMIN) Checklist (Continued)

\begin{tabular}{|c|c|c|c|c|c|c|c|c|c|c|c|}
\hline & $\begin{array}{l}\text { Gobbens et al. } \\
\text { [92] }\end{array}$ & 0 & 0 & 0 & 0 & 0 & 2 & 0 & 0 & 0 & \\
\hline & $\begin{array}{l}\text { Gobbens et al. } \\
\text { [93] }\end{array}$ & 0 & 0 & 0 & 0 & 0 & 2 & 0 & 0 & 0 & \\
\hline & $\begin{array}{l}\text { Metzelthin et al. } \\
\text { [57] }\end{array}$ & - & 0 & 0 & 0 & - & 3 & 0 & 1 & 0 & $\begin{array}{l}\text { Internal Consistency and Structural } \\
\text { Validity: Not rated according to } \\
\text { COSMIN guidance as the tool is based } \\
\text { on a formative model. } \\
\text { Criterion Validity: The criterion } \\
\text { employed cannot be considered as a } \\
\text { reasonable gold standard. }\end{array}$ \\
\hline & $\begin{array}{l}\text { Uchmanowicz } \\
\text { et al. [94] }\end{array}$ & - & 0 & 0 & 0 & 0 & 0 & 1 & 0 & 0 & $\begin{array}{l}\text { Internal Consistency: Not rated } \\
\text { according to COSMIN guidance as the } \\
\text { tool is based on a formative model. } \\
\text { Cross Cultural Validity: Multiple-group } \\
\text { confirmatory factor analysis not } \\
\text { performed. }\end{array}$ \\
\hline $\begin{array}{l}\text { WHIOS Multicomponent } \\
\text { Measure }\end{array}$ & $\begin{array}{l}\text { Woods et al. } \\
\text { [95] }\end{array}$ & 0 & 0 & 0 & 0 & 0 & 2 & 0 & 0 & 0 & \\
\hline
\end{tabular}

Key: 4: Excellent, 3: Good, 2: Fair, 1: Poor, 0: No information, - : Not rated

AUC Area Under Curve, ROC Receiver Operating Curve 
Screening Tool for Frailty [73], The Fatigue Resistance Ambulation Illnesses Loss of Weight (FRAIL) Scale [87] and Women's Health Initiative Observational Study (WHIOS) Multicomponent Measure [95]. Each of these tools had only one element of Construct Validity (Hypothesis Testing) explored.

Overall Internal Consistency was assessed in 7/38 tools [29, 41, 51, 54, 57, 58, 61, 79, 84, 85, 94]; Internal Consistency was determined via Cronbach $\alpha$ calculations for $6 / 7$ tools, the scores of which ranged from 0.62 for the Edmonton Frail Scale (EFS) [42] to 0.81 for The Comprehensive Frailty Assessment Instrument [84]. Reliability was assessed in $8 / 38$ tools [31, 34, 39, 41, 44, 45, 61, 91]. Inter-rater reliability was assessed for $8 / 38$ tools [31, 34, $39,41,44,45,61,91]$ and was most commonly assessed using Cohen's Kappa calculations, the scores of which ranged from 0.63 for the Easycare- Two-step Older persons Screening (EASY-Care TOS) [39] to 0.72 for the Evaluative Index for Physical Frailty (EIPF) [44]. Intrarater reliability was assessed for the EIPF only using Cohen's Kappa calculations and Intraclass Correlation Coefficient calculations [44]. Test-retest reliability was assessed for the TFI only using Pearson Correlation Coefficient calculations [91]. Measurement Error was not assessed for any tool.

Construct Validity was the most widely evaluated measurement property, and was assessed in 36/38 tools [2, 13, 25-28, 30-33, 35-95]. The Clinical Global Impression of Change in Physical Frailty [34] and the British Frailty Index (BFI) [29] were the only tools for which Construct Validity was not assessed. Structural Validity was assessed in 12/38 tools [25, 35, 51, 53, 54, 57, 58, 67, 71, 72, 74, 79, 84]. Exploratory and Confirmatory Factor Analysis were the most common statistical methods employed to determine structural validity. Hypothesis Testing was assessed in 33/38 tools [2, 13, 25-28, $30-33,35-39,42-50,52-68,71-81,83,85-87,89$, 91-93, 95]. Hazard and Odds Ratios were the most frequently employed method of statistical analysis used to establish predictive validity as part of Hypothesis Testing. Cross Cultural Validity was assessed in one tool; the TFI [88, 94]. Content Validity was assessed in $28 / 38$ tools $[25,28,30,31,34,35,38,40,44,45,49-54,61,66$, $67,74,79,82,84,86,90,91]$. Criterion Validity was assessed in 18/38 tools [26, 29-32, 38, 39, 46, 49, 52, 54-57, 60, 67-70, 74, 75, 78, 81, 85, 86]. Receiver Operating Characteristic curve analysis was the most frequently employed method of statistical analysis to determine Criterion Validity. Responsiveness was assessed in 2/38 tool; the GFI and TFI [55]. Additional file 1 provides an overview of the statistical analysis employed in each study to assess the identified measurement properties.

Table 2 summarises the measurement properties evaluated for each tool for which the supporting evidence was within statistically significant parameters and the evidence was rated as fair', good' or excellent' according to the COSMIN checklist. Evidence of Internal Consistency and Structural Validity was excluded following COSMIN guidance as items of a measurement tool do not need to be correlated when a tool is based on a formative model [21-23].

In terms of the individual measurement properties that were evaluated, 2/38 frailty assessment tools had Reliability data within statistically significant parameters of fairexcellent quality; the FI-CGA [45-47] and TFI [45, 91]. 18/38 tools had Content Validity of fair-excellent quality within statistically significant parameters $[25,26,30-38$, $44-47,49,50,54-62,64-67,74-79,84-86,88-94]$ ] 30/38 tools had evidence for Hypothesis Testing [2, 13, 25-28, 30-32, 35-39, 42, 45-50, 54-67, 71-81, 83, 85-87, 89, 91-93, 95] and 2/38 had evidence of Responsiveness; the GFI and TFI [55].

The TFI and the FI-CGA were the only tools which had both reliability and validity data within statistically significant parameters of fair-excellent quality [45-47, $55,57,88-94]$. The TFI had acceptable evidence of psychometric testing for 4 measurement domains; Reliability, Content Validity, Hypothesis Testing and Responsiveness. The FI-CGA had acceptable evidence of psychometric testing for 3 measurement domains; Reliability, Content Validity and Hypothesis Testing. The following tools were found to have no reliability or validity evidence of fairexcellent quality within statistically significant parameters; BFI [29], EFS [41, 42], Frailty Index for Elders [51], Frail Non-Disabled Instrument [52], Frailty Screening Tool [53], Marigliano-Cacciafesta Polypathological Scale [68] and Strawbridge Frailty Measure [82, 83].

\section{Discussion}

To the authors' knowledge this is the first review of the overall reliability and validity of multi-component frailty assessment tools that were specifically developed to assess frailty in older adult populations. This review presents a comprehensive list of multi-component frailty assessment tools for which there are published psychometric data.

Whilst 73 papers met the inclusion criteria for review, many more were excluded as they directly or indirectly reported on the psychometric evaluation of an amended version of an established frailty assessment tool. This was predominantly observed in relation to the $\mathrm{CHS}$ Phenotype Model [13] and the CSHA Cumulative Deficit Model [14], where modified versions of Fried's Phenotype of Frailty tool and Mitinski's Frailty Index were applied. While evidence from such studies supports the robustness of these models to conceptualise frailty, it does not provide evidence for the reliability or validity of the original assessment tool. This application of nonstandardised versions of frailty assessment tools within 
Table 2 A summary of the measurement properties of multicomponent frailty assessment tools with evidence of reliability and validity that was within statistical significant parameters and of fair to excellent quality

\begin{tabular}{|c|c|c|c|c|c|c|c|c|c|}
\hline Frailty assessment tool & $\begin{array}{l}\text { Internal } \\
\text { consistency }\end{array}$ & Reliability & $\begin{array}{l}\text { Measurement } \\
\text { error }\end{array}$ & $\begin{array}{l}\text { Content } \\
\text { validity }\end{array}$ & $\begin{array}{l}\text { Structural } \\
\text { validity }\end{array}$ & $\begin{array}{l}\text { Hypothesis } \\
\text { testing }\end{array}$ & $\begin{array}{l}\text { Cross cultural } \\
\text { validity }\end{array}$ & $\begin{array}{l}\text { Criterion } \\
\text { validity }\end{array}$ & Responsiveness \\
\hline 9-Item Frailty Measure [25] & & & & $x$ & & $x$ & & & \\
\hline $\begin{array}{l}\text { Brief Clinical Instrument to } \\
\text { Classify Frailty }[26,27]\end{array}$ & & & & & & $x$ & & & \\
\hline Brief Frailty Index [28] & & & & $x$ & & $x$ & & & \\
\hline \multicolumn{10}{|l|}{ British Frailty Index [29] } \\
\hline $\begin{array}{l}\text { Care Partners-Frailty Index- } \\
\text { Comprehensive Geriatric } \\
\text { Assessment [30] }\end{array}$ & & & & $x$ & & $x$ & & & \\
\hline Clinical Frailty Scale [31-33] & & & & $x$ & & $x$ & & & \\
\hline $\begin{array}{l}\text { Clinical Global Impression of } \\
\text { Change in Physical Frailty [34] }\end{array}$ & & & & $x$ & & & & & \\
\hline $\begin{array}{l}\text { Comprehensive Assessment of } \\
\text { Frailty [35-37] }\end{array}$ & & & & & & $x$ & & & \\
\hline $\begin{array}{l}\text { Continuous Composite Measure } \\
\text { of Frailty [38] }\end{array}$ & & & & $x$ & & $x$ & & & \\
\hline $\begin{array}{l}\text { EASY-Care Two-step Older } \\
\text { persons Screening }[39,40]\end{array}$ & & & & & & $x$ & & & \\
\hline \multicolumn{10}{|l|}{ Edmonton Frail Scale [41-43] } \\
\hline $\begin{array}{l}\text { Evaluative Index for Physical } \\
\text { Frailty [44] }\end{array}$ & & & & $x$ & & & & & \\
\hline FI-CGA [45-47] & & $x$ & & $x$ & & $x$ & & & \\
\hline FORECAST $[35,36]$ & & & & & & $x$ & & & \\
\hline Frailty Index [48] & & & & & & $x$ & & & \\
\hline $\begin{array}{l}\text { Frailty Index based on Primary } \\
\text { Care Data }[49,50]\end{array}$ & & & & $x$ & & $x$ & & & \\
\hline \multicolumn{10}{|l|}{ Frailty Index for Elders [51] } \\
\hline \multicolumn{10}{|l|}{$\begin{array}{l}\text { Frail Non-Disabled Instrument } \\
\text { [52] }\end{array}$} \\
\hline \multicolumn{10}{|l|}{ Frailty Screening Tool [53] } \\
\hline $\begin{array}{l}\text { Groningen Frailty Indicator } \\
{[27,49,54-62]}\end{array}$ & & & & $x$ & & $x$ & & & $x$ \\
\hline Guilley Frailty Instrument [63] & & & & & & $x$ & & & \\
\hline $\begin{array}{l}\text { Inactivity and Weight Loss } \\
{[64,65]}\end{array}$ & & & & $x$ & & $x$ & & & \\
\hline $\begin{array}{l}\text { INTER-FRAIL Study Questionnaire } \\
\text { [66] }\end{array}$ & & & & $x$ & & $x$ & & & \\
\hline KLoSHA Frailty Index [67] & & & & $x$ & & $x$ & & & \\
\hline \multicolumn{10}{|l|}{$\begin{array}{l}\text { Marigliano-Cacciafesta } \\
\text { Polypathological Scale [68] }\end{array}$} \\
\hline $\begin{array}{l}\text { Phenotype of Frailty } \\
{[2,13,27,69,70]}\end{array}$ & & & & & & $x$ & & & \\
\hline $\begin{array}{l}\text { Predictive Physical Frailty Score } \\
\text { [71] }\end{array}$ & & & & & & $x$ & & & \\
\hline Prognostic Risk Score [72] & & & & & & $x$ & & & \\
\hline Self-Report Screening Tool for & & & & & & $x$ & & & \\
\hline
\end{tabular}


Table 2 A summary of the measurement properties of multicomponent frailty assessment tools with evidence of reliability and validity that was within statistical significant parameters and of fair to excellent quality (Continued)

\begin{tabular}{|c|c|c|c|c|}
\hline SHARE Frailty Instrument [74-78] & & $x$ & $x$ & \\
\hline $\begin{array}{l}\text { SHARE Frailty Instrument } 75+ \\
\text { [79] }\end{array}$ & & $x$ & $x$ & \\
\hline SOF Frailty Criteria $[80,81]$ & & & $x$ & \\
\hline \multicolumn{5}{|l|}{$\begin{array}{l}\text { Strawbridge Frailty Measure } \\
{[82,83]}\end{array}$} \\
\hline $\begin{array}{l}\text { The Comprehensive Frailty } \\
\text { Assessment Instrument }[84,85]\end{array}$ & & $x$ & $x$ & \\
\hline The Frailty Trait Scale [86] & & $x$ & $x$ & \\
\hline The FRAIL Scale [87] & & & $x$ & \\
\hline $\begin{array}{l}\text { Tilburg Frailty Indicator (TFI) } \\
{[55,57,88-94]}\end{array}$ & $x$ & $x$ & $x$ & $x$ \\
\hline $\begin{array}{l}\text { WHIOS Multicomponent Measure } \\
\text { [95] }\end{array}$ & & & $x$ & \\
\hline
\end{tabular}

frailty research significantly limits conclusions that can be drawn regarding reliability and validity. It is notable that the CSHA Cumulative Deficit Model is not prescriptive regarding the exact age-related deficits to be included in a Frailty Index, nor the exact number of deficits [14]. A wide range of non-standardised Frailty Indexes were identified in the literature, which was outside of the scope of this review to explore; a recent systematic review by Drubbel et al. [18] specifically explored the criterion validity, construct validity and responsiveness of the Frailty Indexes when applied in a community-dwelling older adult population.

It was observed that many of the frailty assessment tools included for review were developed and tested retrospectively using data available from large-scale longitudinal studies or were developed in conjunction with a larger trial; the main aim of which was not the development of a frailty assessment tool. This lack of focused primary research may partly explain why there are limited reliability and validity data of high quality for many of the tools identified.

In summary, the GFI and TFI were the most frequently examined tools with respect to psychometric properties (11 and 9 studies respectively). 22/38 tools identified had only 1 study concerning psychometric properties; this limited evidence-base reduces the generalisability of the results and conclusions that can be drawn.

Health measurement instruments must be both reliable and valid to ensure diagnostic accuracy and consistency in measurement [23]. Of the 38 multi-component frailty assessment tools identified, no tool has been examined in all reliability and validity domains assessed by the COSMIN checklist. The TFI and GFI had the most psychometric domains explored (8/9 and 7/9 domains, respectively). However, not all of this evidence was assessed to be of fair-excellent quality within statistically significant parameters. Only the TFI and FI-CGA had reliability and validity data within statistically significant parameters of fair-excellent quality. The TFI had acceptable evidence of psychometric testing for 4 measurement domains, while the FI-CGA had acceptable evidence of psychometric testing for 3 measurement domains.

\section{Research and clinical implications}

The frailty assessment tool that has been most extensively examined in terms of its psychometric properties and has the most robust evidence supporting its reliability and validity is the TFI. However, for a frailty assessment tool to meet the requirements of a gold standard it must be based on a universally accepted operational definition of frailty and have evidence pertaining to all aspects of the tool's reliability and validity of high methodological quality [9]. Further research of good-excellent quality is needed, encompassing all aspects of reliability and validity, before the TFI tool can be classified as a gold standard.

The application of a tool without a strong evidencebase of reliability and validity significantly increases the risk of invalid assessment and misdiagnosis of frailty. The consequent implications for research are substantial, including an increased likelihood of the interpretation and reporting of flawed results. The implications for treatment provision and patient outcomes in a clinical setting are also substantial; with potential for decreased recognition of risks for adverse outcomes, inappropriate treatment planning and inappropriate allocation of resources including unsuitable provision of preventative and restorative interventions. Therefore, the scope and quality of reliability and validity evidence must be considered when selecting an assessment tool in both settings. Other key considerations that are important to note when selecting a frailty assessment tool are the interpretability and generalisability of the evidence-base. Evidence of the 
reliability and validity of an assessment tool relates only to its application within the specific setting and population that it was developed for and validated in. The utility of the tool should also be considered, specifically the appropriateness of the mode of administration in relation to the setting and the time and resource demands associated with the tool.

The development and psychometric evaluation of frailty assessment tools should be the primary focus of research projects to further develop a strong evidence-base. When evaluating existing tools, studies should apply a standardised version where feasible. The consensus on a universally accepted operational definition of frailty should also be a key focus of future frailty research to support the development of a gold standard frailty assessment tool.

\section{Limitations of the review}

The selection of studies for inclusion was completed by the lead author (JLS) only, which increased the potential for selection bias; this risk was minimised by following a comprehensive search strategy and the PRISMA standards for reporting in systematic reviews [24]. Studies examining tools that were not specifically developed to assess frailty were excluded; this resulted in the exclusion of some tools such as the Short Physical Performance Battery [96] and Comprehensive Geriatric Assessment [97] which have been referred to in the frailty literature as tools with potential utility in assessing frailty as part of a wider comprehensive assessment. This limits the scope of this review, but was considered reasonable given the complexity of the frailty syndrome. Studies which directly or indirectly reported on the psychometric evaluation of an amended version of an established frailty assessment tool were also excluded. This again limits the scope of the review but was considered reasonable due to the large number of studies citing modified tools identified in the literature and the large variation in the types of modifications.

The COSMIN checklist has several limitations in its application. When assessing Criterion Validity the COSMIN checklist requires the comparator tool to be of a gold standard. There is currently no gold standard frailty assessment tool. Thus, whilst the majority of studies included for review assessing Criterion Validity compared one frailty assessment tool to another widelyused tool, the COSMIN guidance stipulated that this should be rated as evidence of poor methodological quality in relation to Criterion Validity. The COSMIN guidance does however allow for this relationship between frailty assessment tools to be rated as part of Construct Validity, so the evidence of validity provided by such studies was still represented in the COSMIN scoring system. With regards to the COSMIN scoring system, the overall methodological quality rating per measurement property is obtained by taking the lowest rating of all the items assessed for that property giving a worst counts score' [21-23]. Occasionally, however, a measurement property scored highly for all items assessed except for one which resulted in a poor' overall score which did not accurately reflect all the presented evidence. Such a measurement property received the same overall rating as measurement properties that had entirely poor ratings for all items. It was not within the scope of this systematic review to differentiate between such ratings on an item by item basis when reporting results. Whilst this is a limitation, receiving a rating of poor' for one item is an indication of inadequate methodological quality so it does not impact on the overall quality assessment. The application of the COSMIN checklist; a standardised tool developed specifically to assess the methodological quality of studies examining the measurement properties of health-related instruments remains a strength of this review.

\section{Conclusions}

This review provides an up-to-date comprehensive list of all multi-component frailty assessment tools for which there is published psychometric data. It identifies a large number of multi-component frailty assessment tools in existence; however, the breadth and quality of the psychometric properties of these tools is limited. Only the FI-CGA [45-47] and TFI [54, 56, 86-94] have both reliability and validity data within statistically significant parameters and of fair-excellent quality. However, this should be interpreted with caution as a score of fair' on the COSMIN checklist means that the evidence is only of questionable quality. At present, the TFI has the most robust evidence-base supporting its reliability and validity in assessing frailty. However, the psychometric properties of the TFI and all other multi-component frailty assessment tools require further in-depth evaluation before they can fulfil the criteria for a gold standard assessment tool, and before definitive conclusions regarding the best tool for use in research and clinical settings can be drawn.

\section{Additional files}

\section{Additional file 1: Summary of Key Quantitative Reliability and Validity Data for Multicomponent Frailty Assessment Tools [98-100]. (DOCX 65 kb)}

Additional file 2: PRISMA Checklist. (DOCX $23 \mathrm{~kb}$ )

Additional file 3: General Characteristics of Studies. (DOCX 44 kb)

Competing interests

The authors declare that they have no competing interests.

Authors' contributions

The research question, concept and design were formulated by JLS, RLG and $\mathrm{RH}$. The trial selection was completed by JLS. Data analysis was completed by JLS, RLG, MCC, EVW, AMB, SD and SPN. Preparation of manuscript completed by JLS. RLG, RJH, MCC, EWW, AMB, SD and SPN reviewed and 
edited the manuscript. All authors have read and approved the final version of the manuscript.

\section{Acknowledgements}

This research was supported by King's College London, South London and Maudsley NHS Foundation Trust, NIHR Dementia Biomedical Research Unit, NIHR Biomedical Research Centre for Mental Health and Middlesex University. The views expressed are those of the authors and not necessarily those of the NHS, the NIHR or the Department of Health. The authors would like to express their gratitude and thanks to all those authors who responded to study queries and data requests. The authors would also like to express their gratitude to the independent reviewers for their many helpful and insightful comments during the process of finalising this manuscript.

\section{Author details}

${ }^{1}$ Department of Old Age Psychiatry, Institute of Psychiatry, Psychology \& Neuroscience, King's College London, Box PO70, De Crespigny Park, London SE5 8AF, UK. ${ }^{2}$ Centre for Dementia Studies, Brighton and Sussex Medical School, East Sussex, UK. ${ }^{3}$ Department of Psychology, School of Science and Technology, Middlesex University, London, UK. Division of Psychiatry, University College London, London, UK.

\section{Received: 27 August 2015 Accepted: 12 February 2016} Published online: 29 February 2016

\section{References}

1. Global Health and Ageing (2011). WHO (Online) Available at: http://www. who.int/ageing/publications/global_health/en/. Accessed: March 032015.

2. Ensrud KE, Ewing SK, Taylor BC, et al. Frailty and risk of falls, fracture, and mortality in older women: the study of osteoporotic fractures. J Gerontol A Biol Sci Med Sci. 2007;62:744-51.

3. Al Snih S, Graham JE, Ray LA, et al. Frailty and incidence of activities of daily living disability among older Mexican Americans. J Rehabil Med. 2009;41:892-7.

4. Boyd CM, Xue QL, Simpson CF, et al. Frailty, hospitalization, and progression of disability in a cohort of disabled older women. Am J Med. 2005;1 18:1225-31.

5. Chang $Y-W$, Chen $W-L$, Lin F-G, et al. Frailty and its impact on healthrelated quality of life: a cross-sectional study on elder communitydwelling preventive health service users. PLoS One. 2012;7(5):e38079. doi:10.1371/journal.pone.0038079.

6. Puts MTE, Lips P, Deeg DJH. Sex Differences in the Risk of Frailty for Mortality Independent of Disability and Chronic Diseases. J Am Geriatr Soc. 2005;53:40-47.

7. Gale CR, Cooper C, Deary IJ, Aihie Sayer A. Psychological well-being and incident frailty in men and women: the English Longitudinal Study of Ageing. Psychol Med. 2014;44:697-706.

8. Collard RM, Boter $\mathrm{H}$, Schoevers RA, et al. Prevalence of frailty in community-dwelling older persons: a systematic review. J Am Geriatr Soc. 2012:60(8):1487-92

9. Rodriguez-Manas L, Feart C, Mann G, et al. Searching for an Operational Definition of Frailty: A Delphi Based Consensus Statement. The frailty operative definition-consensus conference project. J Gerontol A Biol Sci Med Sci. 2013;68(1):62-7.

10. Clegg A, Young J, lliffe S, et al. Frailty in elderly people. Lancet. 2013;381:752-62.

11. Fried LP, Ferrucci L, Darer J, et al. Untangling the concepts of disability, frailty, and comorbidity: implications for improved targeting and care. J Gerontol: Med Sci. 2004;59:255-63.

12. Lang PO, Michel JP, Zekry D. Frailty syndrome: a transitional state in a dynamic process. Gerontology. 2009;55:539-49.

13. Fried LP, Tangen CM, Walston J, et al. Frailty in older adults: evidence for a phenotype. J Gerontol: Med Sci. 2001;56A(3):146-56.

14. Mitnitski AB, Mogilner AJ, Rockwood K. Accumulation of deficits as a proxy measure of aging. Sci World. 2001;1:323-36. doi:10.1100/tsw.2001.58 Available from: ISSN 1532-2246; [Accessed: 03/10/2014].

15. Sternberg S, Wershof Schwartz A, Karunananthan S, et al. The identification of frailty: a systematic literature review. J Am Geriatr Soc. 2011;59:2129-38.

16. Clegg A, Rogers $L$, Young J. Diagnostic test accuracy of simple instruments for identifying frailty in community-dwelling older people: a systematic review. Age Ageing. 2015:44(1):148-52.

17. Pijpers E, Ferreira I, Stehouwer CD, Nieuwenhuijzen Kruseman AC. The frailty dilemma. Review of the predictive accuracy of major frailty scores. Eur J Intern Med. 2012;23(2):118-23.
18. Drubbel I, Numans ME, Kranenburg G, et al. Screening for frailty in primary care: A systematic review of the psychometric properties of the frailty index in community-dwelling older people. BMC Geriatr. 2014;14:27.

19. de Vries NM, Staal JB, van Ravensberg CD, et al. Outcome instruments to measure frailty: a systematic review. Ageing Res Rev. 2011;10(1):104-14.

20. Bouillon K, Kivimaki M, Hamer M, et al. Measures of frailty in populationbased studies: an overview. BMC Geriatr. 2013;13:64.

21. Terwee $\mathrm{CB}$, Mokkink LB, Knol DL, et al. Rating the methodological quality in systematic reviews of studies on measurement properties: A scoring system for the COSMIN checklist. Qual Life Res. 2012;21:651-7.

22. Mokkink LB, Terwee CB, Patrick DL, et al. The COSMIN study reached international consensus on taxonomy, terminology, and definitions of measurement properties for health-related patient-reported outcomes. J Clin Epidemol. 2010;63:737-45.

23. Mokkink LB, Terwee CB, Patrick DL, et al. The COSMIN checklist for assessing the methodological quality of studies on measurement properties of health status measurement instruments: an international Delphi study. Qual Life Res. 2010;19:539-49.

24. Moher D, Liberati A, Tetzlaff J, Altman DG, The PRISMA Group, Preferred Reporting Items for Systematic Reviews and Meta-Analyses: The PRISMA Statement. BMJ. 2009;339:b2535. doi:10.1136/bmj.b2535.

25. Ravaglia G, Forti P, Lucicesare A, et al. Development of an easy prognostic score for frailty outcomes in the aged. Age Ageing. 2008;37(2):161-6.

26. Rockwood K, Stadnyk K, Macknight C, et al. A brief clinical instrument to classify frailty in elderly people. Lancet. 1999;353(9148):205-6.

27. Kenig J, Zychiewicz B, Olszewska U, Richter P. Screening for frailty among older patients with cancer that qualify for abdominal surgery. J Geriatr Oncol. 2015;6(1):52-9.

28. Freiheit EA, Hogan DB, Eliasziw M, et al. Development of a frailty index for patients with coronary artery disease. J Am Geriatr Soc. 2010;58(8):1526-31.

29. Kamaruzzaman S, Ploubidis GB, Fletcher A, Ebrahim S. A reliable measure of frailty for a community dwelling older population. Health Qual Life Outcomes. 2010;8:123

30. Goldstein J, Hubbard RE, Moorhouse P, et al. The validation of a care partner-derived frailty index based upon comprehensive geriatric assessment (CP-FI-CGA) in emergency medical services and geriatric ambulatory care. Age Ageing. 2015;44(2):327-30.

31. Rockwood K, Song X, MacKnight C, et al. A global clinical measure of fitness and frailty in elderly people. Can Med Assoc J. 2005;173(5):489-95.

32. Rockwood K, Abeysundera MJ, Mitnitski A. How should we grade frailty in nursing home patients? J Am Med Dir Assoc. 2007;8(9):595-603.

33. Mitnitski A, Fallah N, Rockwood MR, Rockwood K. Transitions in cognitive status in relation to frailty in older adults: a comparison of three frailty measures. J Nutr Health Aging. 2011;15(10):863-7.

34. Studenski S, Hayes RP, Leibowitz RQ, et al. Clinical global impression of change in physical frailty: development of a measure based on clinical judgment. J Am Geriatr Soc. 2004;52(9):1560-6.

35. Sundermann S, Dademasch A, Praetorius J, et al. Comprehensive assessment of frailty for elderly high-risk patients undergoing cardiac surgery. Eur J Cardiothorac Surg. 2011;39(1):33-7.

36. Sundermann S, Dademasch A, Rastan A, Praetorius J, Rodriguez H, Walther T, et al. One-year follow-up of patients undergoing elective cardiac surgery assessed with the Comprehensive Assessment of Frailty test and its simplified form. Interact Cardiovasc Thorac Surg. 2011;13(2):119-23.

37. Sundermann $\mathrm{SH}$, Dademasch A, Seifert B, et al. Frailty is a predictor of shortand mid-term mortality after elective cardiac surgery independently of age. Interact Cardiovasc Thorac Surg. 2014;18(5):580-5.

38. Buchman AS, Wilson RS, Bienias $J$, Bennett DA. Change in frailty and risk of death in older persons. Exp Aging Res. 2009;35(1):61-82.

39. van Kempen JA, Schers HJ, Melis RJ, Olde Rikkert MG. Construct validity and reliability of a two-step tool for the identification of frail older people in primary care. J Clin Epidemiol. 2014;67(2):176-83.

40. van Kempen JA, Schers HJ, Jacobs A, et al. Development of an instrument for the identification of frail older people as a target population for integrated care. Br J Gen Pract. 2013;63(608):e225-31.

41. Rolfson DB, Majumdar SR, Tsuyuki R, et al. Validity and reliability of the Edmonton Frail Scale. Age Ageing. 2006;35(5):526-9.

42. Haley MN, Wells YD, Holland AE. Relationship between frailty and discharge outcomes in subacute care. Aust Health Rev. 2014;38(1):25-9.

43. Graham MM, Galbraith D, O'Neill D, et al. Frailty and outcome in elderly patients with acute coronary syndrome. Can J Cardiol. 2013;29:1610-5. 
44. de Vries NM, Staal JB, Olde Rikkert MG, Nijhuis-van der Sanden MW. Evaluative frailty index for physical activity (EFIP): a reliable and valid instrument to measure changes in level of frailty. Phys Ther. 2013;93(4):551-61.

45. Jones DM, Song $X$, Rockwood K. Operationalizing a frailty index from a standardized comprehensive geriatric assessment. J Am Geriatr Soc. 2004:52(11):1929-33.

46. Jones D, Song X, Mitnitski A, Rockwood K. Evaluation of a frailty index based on a comprehensive geriatric assessment in a population based study of elderly Canadians. Aging Clin Exp Res. 2005;17(6):465-71.

47. Pilotto A, Rengo F, Marchionni N, et al. Comparing the prognostic accuracy for all-cause mortality of frailty instruments: a multicentre 1-year follow-up in hospitalized older patients. PLoS One. 2012;7(1):e29090. doi:10.1371/journal.pone.0029090.

48. Mitnitski AB, Graham JE, Mogilner AJ, Rockwood K. Frailty, fitness and latelife mortality in relation to chronological and biological age. BMC Geriatr. 2002;2:1. doi:10.1186/1471-2318-2-1

49. Drubbel I, Bleijenberg N, Kranenburg G, et al. Identifying frailty: do the Frailty Index and Groningen Frailty Indicator cover different clinical perspectives? A cross-sectional study. BMC Fam Pract. 2013;14:64.

50. Drubbel I, de Wit NJ, Bleijenberg N, et al. Prediction of adverse health outcomes in older people using a frailty index based on routine primary care data. J Gerontol A Biol Sci Med Sci. 2013;68(3):301-8.

51. Tocchi C, Dixon J, Naylor M, et al. Development of a frailty measure for older adults: the frailty index for elders. J Nurs Meas. 2014;22(2):223-40.

52. Cesari $M$, Demougeot $L$, Boccalon $H$, et al. A self-reported screening tool for detecting community-dwelling older persons with frailty syndrome in the absence of mobility disability: the FiND questionnaire. PLoS One. 2014;9(7):e101745.

53. Doba N, Tokuda Y, Goldstein NE, et al. A pilot trial to predict frailty syndrome: the Japanese Health Research Volunteer Study. Exp Gerontol. 2012;47(8):638-43.

54. Bielderman A, van der Schans CP, van Lieshout MR, et al. Multidimensional structure of the Groningen Frailty Indicator in community-dwelling older people. BMC Geriatr. 2013;13:86

55. Daniels R, van Rossum E, Beurskens A, et al. The predictive validity of three self-report screening instruments for identifying frail older people in the community. BMC Public Health. 2012;12:69.

56. Hoogendijk EO, van der Horst HE, Deeg DJ, et al. The identification of frail older adults in primary care: comparing the accuracy of five simple instruments. Age Ageing. 2013:42(2):262-5.

57. Metzelthin SF, Daniels R, van Rossum E, et al. The psychometric properties of three self-report screening instruments for identifying frail older people in the community. BMC Public Health. 2010;10:176.

58. Peters $L L$, Boter H, Buskens E, Slaets JPJ. Measurement properties of the groningen frailty indicator in home-dwelling and institutionalized elderly people. JAMDA. 2012;13:546-51.

59. Schuurmans $H$, Steverink N, Lindenberg $S$, et al. Old or frail: what tells us more? J Gerontol A Biol Sci Med Sci. 2004;59A(9):962-5.

60. Smets $\mid \mathrm{H}$, Kempen $\mathrm{Gl}$, Janssen-Heijnen $\mathrm{ML}$, et al. Four screening instruments for frailty in older patients with and without cancer: a diagnostic study. BMC Geriatr. 2014:14:26

61. Steverink N, Slates JPJ, Schuurmans $H$, van Lis M. Measuring frailty: Developing and testing the GFI (Groningen Frailty indicatior). Gerontologist. 2001:41(1):236-7.

62. Tegels JJ, de Maat MF, Hulsewe KW, et al. Value of geriatric frailty and nutritional status assessment in predicting postoperative mortality in gastric cancer surgery. J Gastrointest Surg. 2014;18(3):439-45.

63. Guilley E, Ghisletta P, Armi F, et al. Dynamics of frailty and dependence in a five-year longitudinal study of octogenarians. Res Aging. 2008;30(3):299-317.

64. Chin A, Paw MJ, Dekker JM, Feskens EJ, et al. How to select a frail elderly population? A comparison of three working definitions. J Clin Epidemiol. 1999;52(11):1015-21.

65. Chin A, Paw MJ, de Groot LC, van Gend SV, et al. Inactivity and weight loss: effective criteria to identify frailty. J Nutr Health Aging. 2003;7(1):55-60.

66. Di Bari M, Profili F, Bandinelli S, et al. Screening for frailty in older adults using a postal questionnaire: rationale, methods, and instruments validation of the INTER-FRAIL study. J Am Geriatr Soc. 2014;62(10):1933-7.

67. Jung H-W, Kim S-W, Ahn S, et al. Prevalence and outcomes of frailty in Korean elderly population: comparisons of a multidimensional frailty index with two phenotype models. PLoS One. 2014;9(2):e87958. doi:10.1371/journal.pone.0087958.
68. Amici A, Baratta A, Linguanti A, et al. The Marigliano-Cacciafesta Polypathological Scale: A tool for assessing fragility. Arch Gerontol Geriatr. 2008;46(3):327-34.

69. Kim H, Higgins PA, Canaday DH, et al. Frailty assessment in the geriatric outpatient clinic. Geriatr Gerontol Int. 2014;14:78-83.

70. Kulminski AM, Ukraintseva SV, Kulminskaya IV, et al. Cumulative deficits better characterize susceptibility to death in elderly people than phenotypic frailty: lessons from the Cardiovascular Health Study. J Am Geriatr Soc. 2008;56(5):898-903.

71. Carriere I, Colvez A, Favier F, et al. Hierarchical components of physical frailty predicted incidence of dependency in a cohort of elderly women. J Clin Epidemiol. 2005;58(11):1180-7.

72. Pijpers E, Ferreira I, van de Laar RJ, et al. Predicting mortality of psychogeriatric patients: a simple prognostic frailty risk score. Postgrad Med J. 2009;85:464-9.

73. de Souto BP, Greig C, Ferrandez A-M. Detecting and categorizing frailty status in older adults using a self-report screening instrument. Arch Gerontol Geriatr. 2012:54:249-54.

74. Romero-Ortuno R, Walsh CD, Lawlor BA, Kenny RA. A frailty instrument for primary care: findings from the Survey of Health, Ageing and Retirement in Europe (SHARE). BMC Geriatr. 2010;10:57.

75. Romero Ortuno R. The Frailty Instrument for primary care of the Survey of Health, Ageing and Retirement in Europe (SHARE-FI): results of the Spanish sample. Rev Esp Geriatr Gerontol. 2011:46(5):243-9.

76. Romero-Ortuno R, O'Shea D, Kenny RA. The SHARE frailty instrument for primary care predicts incident disability in a European population-based sample. Qual Prim Care. 2011;19(5):301-9.

77. Romero-Ortuno R. The SHARE operationalized frailty phenotype: A comparison of two approaches. Eur Geriatr Med. 2013;4:255-9.

78. Romero-Ortuno R. The frailty instrument for primary care of the survey of health, ageing and retirement in Europe predicts mortality similarly to a frailty index based on comprehensive geriatric assessment. Geriatr Gerontol Int. 2013;13(2):497-504.

79. Romero-Ortuno R, Soraghan C. A Frailty Instrument for primary care for those aged 75 years or more: findings from the Survey of Health, Ageing and Retirement in Europe, a longitudinal population-based cohort study (SHAREFl75+). BMJ Open. 2014:4:e006645, doi:10.1136/bmjopen-2014-006645.

80. Bilotta C, Nicolini P, Case A, et al. Frailty syndrome diagnosed according to the Study of Osteoporotic Fractures (SOF) criteria and adverse health outcomes among community-dwelling older outpatients in Italy. A oneyear prospective cohort study. Arch Gerontol Geriatr. 2012;54(2):23-8.

81. Ensrud KE, Ewing SK, Taylor BC, et al. Comparison of 2 frailty indexes for prediction of falls, disability, fractures, and death in older women. Arch Intern Med. 2008;168(4):382-9.

82. Strawbridge WJ, Shema SJ, Balfour JL, et al. Antecedents of frailty over three decades in an older cohort. J Gerontol B Psychol Sci Soc Sci. 1998:53(1):9-16.

83. Matthews M, Lucas A, Boland R, et al. Use of a questionnaire to screen for frailty in the elderly: An exploratory study. Aging Clin Exp Res. 2004;16:34-40.

84. De Witte N, Gobbens R, De Donder L, et al. The comprehensive frailty assessment instrument: development, validity and reliability. Geriatr Nurs. 2013;34(4):274-81

85. De Witte N, Gobbens R, De Donder L, et al. Validation of the comprehensive frailty assessment instrument against the tilburg frailty indicator. Eur Geriatr Med. 2013:4:248-54.

86. Garcia-Garcia FJ, Carcaillon L, Fernandez-Tresguerres J, et al. A new operational definition of frailty: the Frailty Trait Scale. J Am Med Dir Assoc. 2014;15(5):371.

87. Lopez D, Flicker L, Dobson A. Validation of the Frail Scale in a cohort of older Australian women. J Am Geriatr Soc Jan. 2012;60(1):171-3.

88. Andreasen J, Sørensen EE, Gobbens RJJ, et al. Danish version of the Tilburg Frailty Indicator-translation, cross-cultural adaption and validity pretest by cognitive interviewing. Arch Gerontol Geriatr. 2014;59(1):32-8.

89. Gobbens RJ, van Assen MA. The prediction of quality of life by physical, psychological and social components of frailty in community-dwelling older people. Qual Life Res. 2014;23(8):2289-300.

90. Gobbens RJJ, van Assen MA, Luijkx KG, et al. Determinants of Frailty. J Am Med Dir Assoc. 2010;10:356-64.

91. Gobbens RJ, van Assen MA, Luijkx KG, et al. The Tilburg Frailty Indicator: psychometric properties. J Am Med Dir Assoc. 2010;11(5):344-55.

92. Gobbens RJJ, van Assen MA, Luijkx KG, Schols JMGA. The predictive validity of the Tilburg Frailty Indicator: Disability, health care utilization, and quality of life in a population at risk. Gerontologist. 2012;52(5):619-31. 
93. Gobbens RJJ, van Assen MALM. Frailty and its prediction of disability and health care utilization: The added value of interviews and physical measures following a self-report questionnaire. Arch Gerontol Geriatr. 2012;55(2):369-79.

94. Uchmanowicz I, Jankowska-Polańska B, Łoboz-Rudnicka M, et al. Crosscultural adaptation and reliability testing of the Tilburg Frailty Indicator for optimizing care of Polish patients with frailty syndrome. Clin Interv Aging. 2014:9:997-1001.

95. Woods NF, LaCroix AZ, Gray SL, et al. Frailty: emergence and consequences in women aged 65 and older in the Women's Health Initiative Observational Study. J Am Geriatr Soc. 2005;53:1321-30.

96. Chang S-F, Yang R-S, Lin T-C, et al. The Discrimination of Using the Short Physical Performance Battery to Screen Frailty for Community-Dwelling Elderly People. J Nurs Scholarsh. 2014;46(3):207-15.

97. Abellan van Kan G, Rolland YM, Morley JE, Vellas B. Frailty: toward a clinical definition. J Am Med Dir Assoc. 2008:9(2):71-2

98. Peacock JL, Peacock PJ. Oxford Handbook of Medical Statistics. 1st ed. New York: Oxford University Press; 2011.

99. De Vet HCW, Trewee LB, Mokkink LB, Knol DL. Measurement in medicine a practical guide. New York: Cambridge University Press; 2011.

100. Hu LT, Bentler PM. Cut off criteria for fit indexes in covariance structure analysis: Conventional criteria versus new alternatives. Struct Equ Model: Multi J. 1999:6(1):1-55. doi:10.1080/10705519909540118.

Submit your next manuscript to BioMed Central and we will help you at every step:

- We accept pre-submission inquiries

- Our selector tool helps you to find the most relevant journal

- We provide round the clock customer support

- Convenient online submission

- Thorough peer review

- Inclusion in PubMed and all major indexing services

- Maximum visibility for your research

Submit your manuscript at www.biomedcentral.com/submit
Biomed Central 